\title{
ON A SUBCLASS OF ANALYTIC CLOSE-TO-CONVEX FUNCTIONS IN $q$-ANALOGUE ASSOCIATED WITH JANOWSKI FUNCTIONS
}

\author{
Bakhtiar Ahmad, Muhammad Farooq and RaEes KHan
}

\begin{abstract}
In this article we define a new subclass of analytic multivalent close-to-convex functions in $q$-calculus associated with Janowski functions. We investigate some geometric properties such as sufficiency criteria, distortion problem, growth theorem, radii of starlikeness and convexity and coefficient estimates for this class.
\end{abstract}

Mathematics subject classification (2010): 30C45, 30C50.

Keywords and phrases: Multivalent analytic functions, starlike functions, close-to-convex functions, Janowski functions.

\section{REFERENCES}

[1] I. Aldawish AND M. DARUS, Starlikeness of q-differential operator involving quantum calculus, Korean J. Math. 22 (4), 699-709 (2014).

[2] H. Aldweby AND M. DARUs, Some subordination results on q-analogue of Ruscheweyh differential operator, Abstr. Appl. Anal., Vol. 2014, Article ID 958563, 6 pages 1-6 (2013).

[3] A. ARAL, On the generalized Picard and Gauss Weierstrass singular integrals, J. Comput. Anal. Appl. 8 (3), 249-261 (2006).

[4] A. Aral, V. Gupta And R. P. Agarwal, Applications of q-Calculus in Operator Theory, Springer-Verlag New York, 2013.

[5] A. Aral And V. Gupta, Generalized q-Baskakov operators, Math. Slovaca 61 (4), 619-634 (2011).

[6] A. Aral And V. Gupta, On q-Baskakov type operators, Demonstr. Math. 42 (1), 109-122 (2009).

[7] G. A. AnASTASSIU AND S. G. GAL, Geometric and approximation properties of generalized singular integrals, J. Korean Math. Soci. 23 (2), 425-443 (2006).

[8] J. Dziok, G. Murugusundaramoorthy And J. Soko€, On certain class of meromorphic functions with positive coefcients, Acta Math. Sci. Ser. B 32 (4), 1-16 (2012).

[9] M. R. GANigi AND B. A. URAlEgAdDI, New criteria for meromorphic univalent functions, Bull. Math. Soc. Sci. Math. Roumanie (N.S.), 33 (81), 9-13 (1989).

[10] A. HUdA AND M. DARUS, Integral operator defined by q-analogue of Liu-Srivastava operator, Studia Universitatis Babes-Bolyai Series Mathematica 58 (4), 529-537 (2013).

[11] F. H. JACKSON, On q-definite integrals, The Quarterly Journal of Pure and Applied Mathematics 41, 193-203 (1910).

[12] F. H. JACKSON, On q-functions and a certain difference operator, Earth and Environmental Science Transactions of The Royal Society of Edinburgh 46 (2), 253-281 (1909).

[13] W. Janows KI, Some extremal problems for certain families of analytic functions, Ann. Polon. Math. 28, 297-326 (1973).

[14] S. Kanas AND D. RĂDUCANU, Some class of analytic functions related to conic domains, Math. Slovaca. 64 (5), 1183-1196 (2014).

[15] S. MAнMmod AND J. SoKóŁ, New subclass of analytic functions in conical domain associated with Ruscheweyh q-differential operator, Results Math. 71 (4), 1345-1357 (2017).

[16] A. Mohammed And M. DARUS, A generalized operator involving the q-hypergeometric function, Mat. vesn. 65 (4), 454-465 (2013).

[17] T. M. SEOUdy AND M. K. Aouf, Coefficient estimates of new classes of $q$-starlike and $q$-convex functions of complex order, J. Math. Inequal. 10 (1), 135-145 (2016). 
[18] H. M. SRIVASTAVA AND D. BAnSAL, Close-to-convexity of a certain family of q-Mittag-Leffler functions, J. Nonlinear Var. Anal. 1 (1), 61-69 (2017).

[19] H. M. SRIVASTAVA, Univalent functions, fractional calculus and associated generalized hypergeometric functions, in Univalent Functions, Fractional Calculus, and Their Applications (H. M. Srivastava and S. Owa, Editors), Halsted Press (Ellis Horwood Limited, Chichester), pp. 329-354, John Wiley and Sons, New York, Chichester, Brisbane and Toronto, 1989.

[20] C. Pommerenke, On meromorphic starlike functions, Pacific J. Math. 13, 221-235 (1963).

[21] W. Rogosinsk, On the coefficients of subordinate functions, Proc. London Math. Soc. 48 (2), 48-82 (1943).

[22] B. A. URAlegaddi And C. Somanatha, Certain diferential operators for meromorphic functions, Houston J. Math. 17 (2), 279-284, (1991).

[23] W. C. Royster, Meromorphic starlike multivalent functions, Trans. Amer. Math. Soc. 107 (1963), 300-308. 